\section{Correspondence}

https://doi.org/10.11646/zootaxa.4415.2.9

http://zoobank.org/urn:lsid:zoobank.org:pub:D2EA6838-50EC-4C44-8016-933AF34B56D2

\title{
Values, regulation, and species delimitation
}

\author{
STIJN CONIX \\ Department of History and Philosophy of Science, University of Cambridge, Free School Lane, CB2 3RE, Cambridge, UK. \\ E-mail:sc881@cam.ac.uk
}

Garnett and Christidis (2017) [hereafter GC] recently proposed that the International Union of the Biological Sciences should centrally regulate the taxonomy of complex organisms. Their proposal was met with much criticism (e.g. Hołyński 2017; Thomson et al., 2018), and perhaps most extensively from Raposo et al. (2017) in this journal. The main target of this criticism was GC's call to, first, "restrict the freedom of taxonomic action", and, second, to let social, political and conservation values weigh in on species classification. Some commentators even went as far as to draw a comparison with the infamous Lysenko-case of state-controlled and heavily restricted science (Raposo et al. 2017, 181; Hołyński 2017, 12). This comment will argue, without thereby endorsing GC's position, that these two aspects of their views need not be as threatening as this comparison suggests, and indeed are very reasonable.

GC's proposal is motivated by what they call a state of 'anarchy' in taxonomy: There is no agreement about how independently evolving lineages are to be defined, and " '[s]pecies' are often created or dismissed arbitrarily, according to the individual taxonomist's adherence to one of at least 30 definitions" (Garnett \& Christidis, 2017, 25). While the use of a rather harsh term like 'anarchy' does not do justice to the sophisticated, rigorous and careful empirical work that characterizes taxonomy, it is hard to deny a grain of truth in their claims. Taxonomists use many different approaches, evidence types, and methods of analysis for species delimitation, and these often lead to diverging results (see e.g. Padial et al. 2009; Satler et al. 2013; Willis, 2017). This 'anarchy' is not a failure of taxonomy, but the inevitable consequence of the complexity of the organic world and the evolutionary processes that shape it. A group of organisms may be evolving independently in some aspects but not in others, and different evidence types and methods pick up on these different aspects (De Queiroz, 2007). One consequence of this is that a single species classification cannot capture all interesting groups at the species level because there are sometimes multiple viable but competing options for species delimitation. This is particularly so when delimiting recently diverged lineages, which are evolving independently in some respects but not in others.

The point here is that if there sometimes are multiple viable options for species delimitation, the choice between these options is not fully determined by the world. Which of these options we end up with may then depend partially on the particular methodological choices of taxonomists, which in turn depend on practical considerations and valuejudgments, e.g. about the price of a method, availability of data, computational power, familiarity with a method, and, according to some, the consequences for the conservation of the group. Schlick-Steiner et al. (2010) call the influence of such considerations 'researcher bias'. Importantly, they point out that while such bias may be reduced by adopting an integrative approach that combines multiple methods and evidence types, it can never be fully eliminated within the means and manpower that can reasonably be devoted to any taxonomic research project. A particularly salient example of such researcher bias is pointed out by Harris and Froufe (2005), who claim that a bias in the geographical origin of taxonomists and the organisms they study has led to low thresholds of genetic divergence for species delimitation.

In short, then, it seems that there are sometimes multiple good options in the classification of organisms, and practical considerations and value-judgments such as the above play an ineliminable role in choosing between these. To these two points we may add that the choice between multiple viable options sometimes has significant epistemic, social, or political consequences through the impact of the outcomes of taxonomy on other scientific work, conservation action and legislation, trade regulation, industry, etc. It is interesting to reconsider GC's proposal with these three points in mind. More precisely, I argue that these three arguably uncontroversial points have in turn three consequences that put at least part of this proposal in a more favourable light than was acknowledged by some of the criticism it received.

First, if we accept that there are sometimes multiple good ways of classifying the same organisms into species (e.g. splitting or lumping two recently diverged lineages), then it is reasonable to let the consequences of choosing either option weigh in on the choice. This position is nicely illustrated by Frankham et al. (2012), who argue that lumping 
groups using a Biological Species Concept is, for conservation reasons, often preferable to splitting groups using a Phylogenetic Species Concept. Note that such a role for social, political or conservation values, which was also highlighted in GC's comment, in no way threatens the objectivity of taxonomy, as it only concerns the choice between various species concepts, and not how these concepts are applied or whether these groups actually exist. Indeed, this role for values is very far removed from the 'wishful thinking' in the Lysenko-era when claims were accepted not on the basis of evidence, but merely because they were in line with a particular ideology. In other words, as long as concerns about "conservation, economic significance, or politic agenda" (Thomson et al., 2018, 7) are restricted to an appropriately restricted role, they need not threaten the scientific character of taxonomy and can even play a positive role.

Second, if we accept that some extent of researcher bias is inevitable in species delimitation, then it is reasonable to strive towards making such bias as explicit as possible. As this bias is usually part of methodological choices and the choice of species concepts, it remains implicit in much current taxonomic work (see Schlick-Steiner et al. 2010) and hence goes unnoticed. GC's proposal of centrally regulated taxonomy would force such bias to be made explicit, and, more importantly, would generate explicit debate about it among taxonomists. For example, in some cases false positives might be more harmful than false negatives or vice versa, while in other cases it is better to suspend judgment about the evolutionary independence of a lineage. While such decisions about the harmful consequences of different kinds of error are now made on a case-by-case basis by taxonomists, often without debate, central regulation of species-level taxonomy would force explicit debate and reflection.

Third, and finally, there are good reasons to install a centralized authority to organize and guide these debates. While there is an important place for special-purpose classifications of organisms, species classification aims to be all-purpose. Such an all-purpose classification should take into account the interests of all stake-holders. Thus, if there are multiple viable options, and values play a role in choosing between these, then the interests of all stakeholders should be taken into account. A centralized authority organising debate between and input from these different stakeholders would be in a good position to ensure this is the case. In light of the worries of Raposo et al. (2017) and Thomson et al. (2018, 8), who claim that regulation and fixation of species delimitation go against the "dynamic nature of taxonomic progress", it is worth pointing out here that such centralized regulation is importantly dissimilar from the regulation that characterized Lysenkoism. While in the latter, debate was not tolerated and dissenting scientists could end up in the Gulags, a centralized authority as proposed by GC would encourage and organize debate and arguments from all points of view. Moreover, central regulation of species classification need not imply that whatever rules are selected cannot be criticized, adapted, and fine-tuned in continued scientific debate.

To illustrate my points, a brief analogy with the measurement of physical quantities will be helpful. While measurement is different from species delimitation in various respects, there are multiple interesting similarities here. In line with GC's proposal about species classification, the definition, modification and calibration of measurement units are regulated by a central authority, namely, the Bureau International des Poids et Mesures (International Bureau of Weights and Measures). Moreover, it is generally accepted that practical considerations and value-judgments play some role in the choice of measurement standards (see Tal, 2016). Nevertheless, it is clear that these standards are not arbitrary, and do, indeed, play a crucial and particularly fruitful role in scientists' efforts of explaining and representing the world. Moreover, the central regulation of these standards has not limited scientific freedom or stifled progress: the definition of standards changes regularly and is the subject of continuous debate among metrologists. Similarly, the influence of value-judgments on the choice of species concepts and the centralized regulation and guidance of debates about this need not constrain scientific freedom or lead to Lysenko-like threats to the objectivity of species delimitation.

All this does not mean that GC's proposal is necessarily the best solution to the problems they start from. If anything, this is hard to evaluate without a detailed plan of how the proposal is to be developed in practice. As Raposo et al. (2017) and Thomson et al. (2018) point out, there are other viable solutions, such as using alternative management units for conservation purposes or adapting conservation legislation, that seem to avoid some of the severe practical problems of GC's proposal (e.g. adding another layer of bureaucracy, diverting funding from already under-funded taxonomic research, etc.). It may be that these solutions are more efficient than GC's proposal. However, it may also be that GC's plan turns out better. The point here is that worries about values and restrictions to scientific freedom should not stop us from further investigating its merits and potential.

\section{Acknowledgements}

I would like to thank an anonymous reviewer for helpful comments. This work was supported by the Arts and Humanities Research Council [AH/14/pool/5]. 


\section{References}

De Queiroz, K. (2007) Species concepts and species delimitation. Systematic Biology, 56.6, 879-86. https://doi.org/10.1080/10635150701701083

Frankham, R., Ballou, J.D., Dudash, M.R., Eldridge, M.D., Fenster, C.B., Lacy, R.C., Mendelson, J.R.I., Porton, I.J., Ralls, K. \& Ryder, O.A. (2012) Implications of different species concepts for conserving biodiversity. Biological Conservation, 153 , 25-31. https://doi.org/10.1016/j.biocon.2012.04.034

Garnett, S.T. \& Christidis, L. (2017) Taxonomy anarchy hampers conservation. Nature, 546, 25-27. https://doi.org/10.1038/546025a

Harris, D.J. \& Froufe, E. (2005) Taxonomic inflation: species concept or historical geopolitical bias? Trends in Ecology \& Evolution, $20(1), 6-7$. https://doi.org/10.1016/j.tree.2004.11.004

Hołyński, R.B. (2017) Taxonomy: should it remain a serious branch of science or be transformed into a formal game? Procrustomachia, 2, 11-13.

Padial, J.M., Castroviejo-Fisher, S., Köhler, J., Vilà, C., Chaparro, J.C. \& De la Riva, I. (2009) Deciphering the products of evolution at the species level: The need for an integrative taxonomy. Zoologica Scripta, 38, 431-447. https://doi.org/10.1111/j.1463-6409.2008.00381.x

Raposo, M.A., Stopiglia, R., Brito, G., Bockmann, F.A., Kirwan, G. M., Gayon, J. \& Dubois, A. (2017) What really hampers taxonomy and conservation? A riposte to Garnett and Christidis (2017). Zootaxa, 4317 (1), 179-184. https://doi.org/10.11646/zootaxa.4317.1.10

Satler, J. D., Carstens, B. C. \& Hedin, M. (2013) Multilocus species delimitation in a complex of morphologically conserved trapdoor spiders (Mygalomorphae, Antrodiaetidae, Aliatypus). Systematic Biology, 62 (6), 805-823. https://doi.org/10.1093/sysbio/syt041

Schlick-Steiner, B.C., Steiner, F.M., Seifert, B., Stauffer, C., Christian, E. \& Crozier, R.H. (2010) Integrative taxonomy: A multisource approach to exploring biodiversity. Annual review of entomology, 55, 421-438. https://doi.org/10.1146/annurev-ento-112408-085432

Tal, E. (2014) Making time: A study in the epistemology of measurement. The British Journal for the Philosophy of Science, 67 (1), $297-335$ https://doi.org/10.1093/bjps/axu037

Thomson, S.A., Pyle, R.L., Ahyong, S., Alonso-Zarazaga, M., Ammirati, J., Araya, J.F., Ascher, J.S., Audisio, T.L., Azevedo-Santos, V.M., Bailly, N., Baker, W.J., Balke, M., Barclay, M.V.L., Barrett, R.L., Benine, R.C., Bickerstaff, J.R.M., Bouchard, P., Bour, R., Bourgoin, T., Boyko, C.B., Breure, A.S.H., Brothers, D.J., Byng, J.W., Campbell, D., Ceríaco, L.M.P., Cernák, I.,Cerretti, P., Chang, C.-H., Cho, S., Copus, J.M., Costello, M.J., Cseh, A., Csuzdi C., Culham, A., D'Elía, G., d'Udekem d'Acoz, C., Daneliya, M.E., Dekker, R., Dickinson, E.C., Dickinson, T.A., van Dijk, P.P., Dijkstra, K.-D.B., Dima, B., Dmitriev, D.A., Duistermaat, L., Dumbacher, J.P., Eiserhardt, W.L., Ekrem, T., Evenhuis, N.L., Faille, A., Fernández-Triana, J.L., Fiesler, E., Fishbein, M., Fordham, B.G., Freitas, A.V.L., Friol, N.R., Fritz, U., Frøslev, T., Funk, V.A., Gaimari, S.D., Garbino, G.S.T., Garraffoni, A.R.S., Geml, J., Gill, A.C., Gray, A., Grazziotin, F.G., Greenslade, P., Gutiérrez, E.E., Harvey, M.S., Hazevoet, C.J., He, K., He, X., Helfer, S., Helgen, K.M., van Heteren, A.H., Hita Garcia, F., Holstein, N., Horváth, M.K., Hovenkamp, P.H., Hwang, W.S., Hyvönen, J., Islam, M.B., Iverson, J.B., Ivie. M.A., Jaafar, J., Jackson, M.D., Jayat, J.P., Johnson, N.F., Kaiser, K., Klitgård, B.B., Knapp, D.G., Kojima, J.-i., Kõljalg U., Kontschán, J., Krell, F.-T., Krisai-Greilhuber, I., Kullander, S., Latella, L., Lattke, J.E., Lencioni, V., Lewis, G.P., Lhano, M.G., Lujan, N.K., Luksenburg, J.A., Mariaux, J., Marinho-Filho, J., Marshall, C.J., Mate, J.F., McDonough, M.M., Michel, E., Miranda, V.F.O., Mitroiu, M.-D., Molinari, J., Monks, S., Moore, A.J., Moratelli, R., Murányi, D., Nakano, T., Nikolaeva, S., Noyes, J., Ohl, M., Oleas, N.H., Orrell, T., Páll-Gergely, B., Pape, T., Papp, V., Parenti, L.R., Patterson, D., Pavlinov, I.Ya., Pine, R.H., Poczai, P., Prado, J., Prathapan, D., Rabeler, R.K., Randall, J.E., Rheindt, F.E., Rhodin, A.G.J., Rodríguez, S.M., Rogers, D.C., Roque, F. de O., Rowe, K.C., Ruedas, L.A., Salazar-Bravo, J., Salvador, R.B., Sangster, G., Sarmiento, C.E., Schigel, D.S., Schmidt, S., Schueler, F.W., Segers, H., Snow, N., Souza-Dias, P.G.B., Stals, R., Stenroos, S., Stone, R.D., Sturm, C.F., Štys, P., Teta, P., Thomas, D.C., Timm, R.M., Tindall, B.J., Todd, J.A., Triebel, D., Valdecasas, A.G., Vizzini, A., Vorontsova, M.S., Vos, J.M. de, Wagner, P., Watling, L., Weakley, A., Welter-Schultes, F., Whitmore, D., Wilding, N., Will, K., Williams, J., Wilson, K., Winston, J.E., Wüster, W., Yanega, D., Yeates, D.K., Zaher, H., Zhang, G., Zhang, Z.-Q., Zhou, H.-Z. (2018) Taxonomy based on science is necessary for global conservation. PLOS Biology, 16 (3), e2005075. https://doi.org/10.1371/journal.pbio.2005075

Willis, S.C. (2017) One species or four? Yes!... and, no. Or, arbitrary assignment of lineages to species obscures the diversification processes of Neotropical fishes. PLoS ONE, 12 (2), e0172349. https://doi.org/10.1371/journal.pone.0172349 